\title{
Protein post-translational modifications and regulation of pluripotency in human stem cells
}

\author{
Yu-Chieh Wang ${ }^{1}$, Suzanne E Peterson ${ }^{1}$, Jeanne F Loring ${ }^{1}$ \\ ${ }^{I}$ Department of Chemical Physiology, Center for Regenerative Medicine, The Scripps Research Institute, 10550 N. Torrey Pines \\ Rd., La Jolla, CA 92037, USA
}

\begin{abstract}
Post-translational modifications (PTMs) are known to be essential mechanisms used by eukaryotic cells to diversify their protein functions and dynamically coordinate their signaling networks. Defects in PTMs have been linked to numerous developmental disorders and human diseases, highlighting the importance of PTMs in maintaining normal cellular states. Human pluripotent stem cells (hPSCs), including embryonic stem cells (hESCs) and induced pluripotent stem cells (hiPSCs), are capable of self-renewal and differentiation into a variety of functional somatic cells; these cells hold a great promise for the advancement of biomedical research and clinical therapy. The mechanisms underlying cellular pluripotency in human cells have been extensively explored in the past decade. In addition to the vast amount of knowledge obtained from the genetic and transcriptional research in hPSCs, there is a rapidly growing interest in the stem cell biology field to examine pluripotency at the protein and PTM level. This review addresses recent progress toward understanding the role of PTMs (glycosylation, phosphorylation, acetylation and methylation) in the regulation of cellular pluripotency.
\end{abstract}

Keywords: post-translational modifications; pluripotency-associated signaling; hESCs; hiPSCs

Cell Research (2014) 24:143-160. doi:10.1038/cr.2013.151; published online 12 November 2013

\section{Introduction}

The ability to self-renew indefinitely and differentiate into all cells of the body makes human pluripotent stem cells (hPSCs), including human embryonic stem cells (hESCs) and induced pluripotent stem cells (hiP$\mathrm{SCs}$ ), valuable for research and clinical applications that require specific cell types. Although recent studies have greatly advanced our understanding of cellular pluripotency and its potential utility, it is still unclear how these cells establish, maintain and modulate their pluripotency during cellular reprogramming and differentiation. Recent evidence indicates that the complex signaling networks involved in the regulation of cellular pluripotency are tightly controlled through multiple mechanisms, including post-translational modifications

Correspondence: Yu-Chieh Wang ${ }^{\mathrm{a}}$, Jeanne F Loring ${ }^{\mathrm{b}}$

${ }^{\mathrm{a}}$ Tel: +1-858-784 7139; Fax: +1-858-784 7211

E-mail: ycwang@scripps.edu

${ }^{\mathrm{b}} \mathrm{Tel}$ : +1-858-784 7362; Fax: +1-858-784 7211

E-mail: jloring@scripps.edu
(PTMs). PTMs diversify and extend protein function beyond what is dictated by gene transcripts. They reversibly or irreversibly alter the structure and properties of proteins through biochemical reactions (Figure 1), and a variety of PTMs allow eukaryotic cells to dynamically regulate their signal integration and physiological states. As analytical approaches have improved, the biological influences of many types of PTMs have been identified and are routinely analyzed in many systems. The importance of PTMs is known historically because of their effects on the enzymatic activity of kinases [1] and protein degradation [2]. Based on previous and emerging data, it seems evident that PTMs are involved in regulating almost all cellular events, including gene expression, signal transduction, protein-protein interaction, cell-cell interaction, and communication between the intracellular and extracellular environment [3]. Therefore, perturbation of PTMs in cells frequently affects cell physiology as a whole. In addition, the alteration of cellular states (e.g., differentiation of hPSCs or malignant transformation of primary cells) may be accompanied by acquisition of unique PTM hallmarks.

In this review, we summarize recent progress in un- 


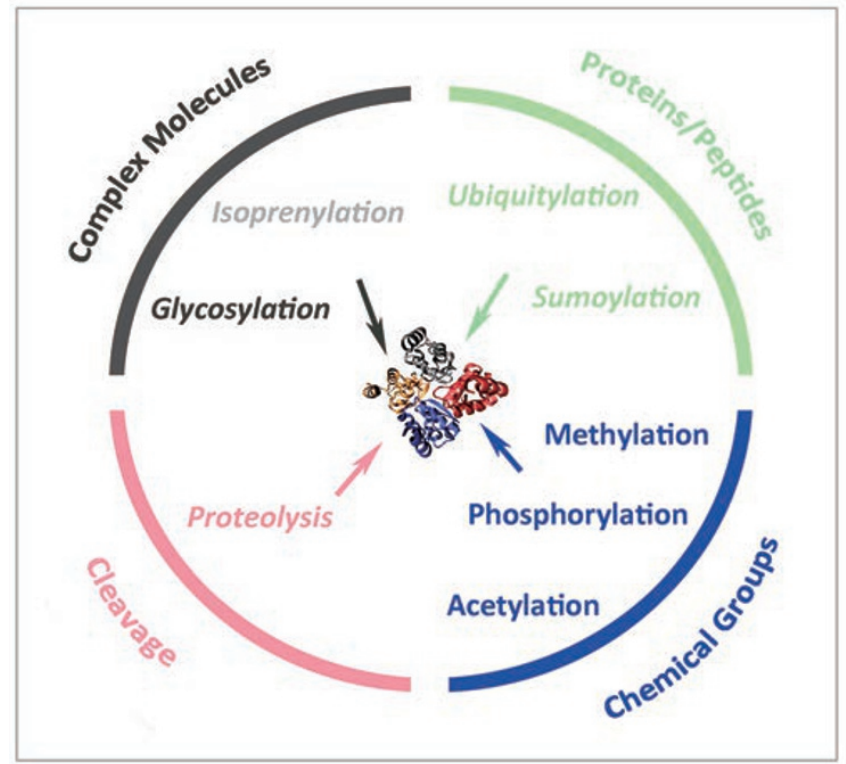

Figure 1 Proteins in eukaryotic cells can be edited after translation by a wide variety of reversible and irreversible PTM mechanisms. The structure, stability and function of proteins in the cells can be dynamically altered by these PTMs. Four types of PTMs (glycosylation, phosphorylation, acetylation and methylation) are indicated by highlighted colors and primarily discussed in this review.

derstanding the roles of PTMs in hPSCs, with particular emphasis on protein glycosylation, phosphorylation, acetylation and methylation. In addition, we discuss how these PTMs may be involved in regulation of the pluripotency and differentiation of hPSCs.

\section{Cellular pluripotency and hPSCs}

Pluripotent stem cells (PSCs) are capable of giving rise to all the differentiated adult cell types. Initially, human embryos acquired from in vitro fertilization procedures were the source material used for isolating pluripotent hESCs from the inner cell mass (ICM) of blastocysts. More recently, the use of defined transcription factors to convert human somatic cells into hiPSCs has become a widely-used approach to establish cellular pluripotency in differentiated cells (Figure 2). In 2013, Tachibana et al. [4] have succeeded in the derivation of hPSCs (nuclear transfer-ESCs) from somatic cell-nuclear transfer human embryos, providing another approach for reprogramming the somatic nuclei to pluripotency.

Since the first method for generating hiPSCs through cellular reprogramming was reported in 2007 [5], a variety of somatic cell types, different combinations of transcription factors and different vehicles to deliver these factors into cells have been used successfully to improve the derivation efficiency of hiPSCs. Over the past six years, extensive research using high-information-content methods to study hESCs and hiPSCs has led to a considerable amount of information about genomic and epigenomic stability, and genome-wide transcriptional and DNA methylation profiles of pluripotent cells. Recent studies indicate that the variation within undifferentiated hiPSC lines is within the range of that seen in hESC lines, suggesting that hiPSCs and hESCs are essentially indistinguishable [6-12]. However, while hPSCs are routinely shown to be capable of differentiation into a wide variety of cell types, there are reports of considerable variation among hPSCs in their response to specific in vitro differentiation protocols [11, 13-15]. These findings suggest that the response of different hPSCs to specific culture conditions may differ even when their gene expression and epigenetic characteristics in the pluripotent state are virtually identical; this raises an intriguing possibility that these responses are controlled at the protein

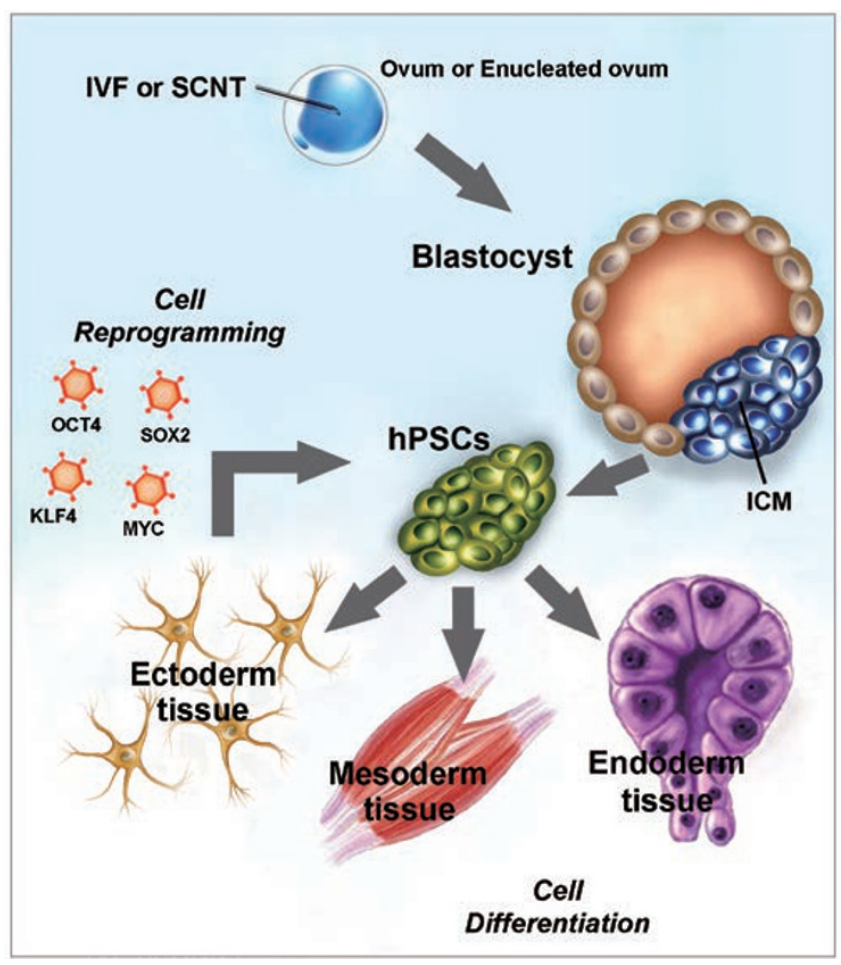

Figure 2 The derivation and differentiation of hPSCs. To obtain hESCs, the inner cell mass of a human blastocyst is isolated and cultured in vitro. To generate hiPSCs, differentiated cells are reprogrammed using a combination of different transcription factors (e.g., OCT4/POU5F1, SOX2, KLF4 and MYC) to establish cellular pluripotency in the cells. Both hESCs and hiPSCs are capable of differentiating into functional cells derived from all the three germ layers in embryos. 


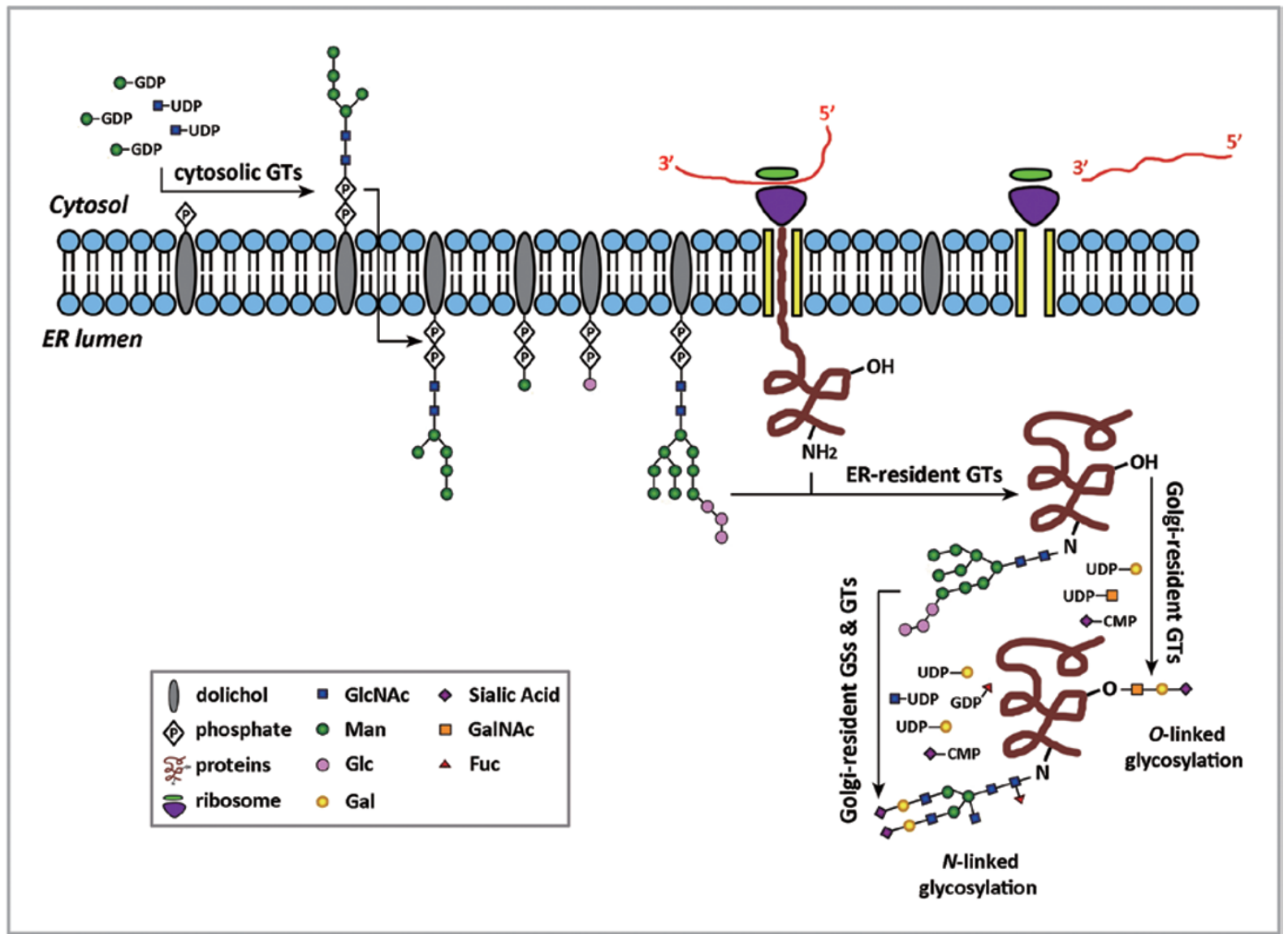

Figure $3 \mathrm{~N}$-linked and O-linked protein glycosylation occurs in the ER and Golgi apparatus. The synthesis of precursor glycans (mannose-rich glycans) begins on the cytosolic face of the ER and is completed after the glycans are flipped into the ER lumen and further branched by adding more units of mannose and glucose. ER-resident glycosyltransferases (GTs) transfer the precursor glycans to asparagine residues on nascent proteins to form $N$-linked precursor glycans. When the proteins are transported into the Golgi apparatus, the $N$-linked precursor glycans are edited by Golgi-resident glycosidases (GSs) and GTs to form mature and structurally-diverse $N$-linked glycans. O-linked protein glycosylation is mainly performed by Golgi-resident GTs.

modification level.

Many systems biology approaches have been applied in the stem cell biology field to acquire global insights into how cellular pluripotency is regulated in both the pluripotent and differentiated states. These types of studies have been usually focused on genomic, epigenetic and transcriptomic characteristics, with less appreciation for the protein expression and PTMs. However, because of the numerous cell activities that are directly governed by proteins, there is no doubt that the regulation of protein components in hPSCs should have profound influences on cellular pluripotency and differentiation capacity. The consequences of altering proteins at the posttranslational level in hPSCs are thus interesting issues applicable to the regulation of pluripotency.

Advances in molecular biology and protein biochemistry have led to the development of several modern technologies to better examine the expression, posttranslational modification and functional alteration of proteins at single-protein and proteomic levels [16-21]. Discoveries based on these methods have shed light on the importance of many PTMs in controlling protein functions, signaling networks and cell fates in hPSCs.

\section{Protein glycosylation in hPSCs}

\section{Glycoproteins and protein glycosylation}

It is well known that protein glycosylation plays a critical role in the regulation of protein structure [22], signal transduction [23], cell-cell and cell-environment interactions [24-26], immune responses [27, 28], hormone action [29], cancer progression [30] and embryonic development $[31,32]$. In the glycosylation process, carbohydrate units can be covalently linked to proteins 
and edited through various biochemical reactions that are catalyzed by glycosyltransferases (GTs) and glycosidases in the endoplasmic reticulum (ER) and Golgi apparatus (Figure 3). There are four major types of protein glycosylation in mammalian cells: $N$-linked glycosylation, $O$-linked glycosylation, $C$-linked mannosylation and glypiation [33]. Among these types of protein glycosylation, $\mathrm{N}$-linked and $\mathrm{O}$-linked glycomodifications are the most abundant in cells. $N$-linked glycosylation often occurs on a large variety of nascent proteins. $O$-linked monosaccharide modification of N-acetylglucosamine (GlcNAc) on serine, threonine or amino acid residues in close proximity to tyrosine phosphorylation sites is frequently observed in many cells. At these sites, glycosylation may contribute to the regulation of signaling pathways through a direct competition with serine and threonine phosphorylation or by indirectly perturbing the phosphorylation of tyrosine [34].

\section{Pluripotency-associated protein glycosylation}

Multiple lines of evidence support the importance of protein glycosylation and its potential role in the regulation of cellular pluripotency and differentiation of hPSCs. Many pluripotency-associated antigens (e.g., SSEA3/4 and TRA1-60/1-81) on the surface of hPSCs are glycoproteins or glycolipids [35-38], implying that specific glycosylation patterns could be hallmarks of cellular pluripotency and that they may be functionally important in its maintenance. Despite the relatively limited sample numbers and types of hPSCs, several studies using mass spectrometry $[39,40]$ to analyze the glycan components of glycoproteins isolated from hPSCs and differentiated cells demonstrated that protein glycosylation differs considerably between pluripotent and non-pluripotent cells. This "glycome shift" occurring in response to a change in pluripotency of human cells has been suggested by many other reports in which certain glycan-binding lectins showed preferential reactivity or cytotoxicity in embryonal carcinoma and germ-cell tumors [41-45]. More recently, several studies have used lectin microarrays and transcriptomic analysis to perform large-scale, highthroughput characterization of protein glycosylation and glycosyltransferase expression in various types of undifferentiated hPSCs and differentiated cells. These studies have provided definitive evidence showing significant differences between the glycomic fingerprints associated with these distinct cellular states [46-48] and led to the identification of a lectin biomarker that can be used to isolate viable hPSCs [48]. Regardless of the different methods used in these studies, their results appear to be in agreement with the idea that two types of glycomodifications, fucosylation and sialylation, are typically altered when hPSCs lose their pluripotency [39, 40, 46, 48, 49]. This suggests that these two types of protein glycosylation may be involved in the regulatory mechanisms underlying cellular pluripotency and lineage specification. In support of this idea, many studies have demonstrated that fucosylation and sialylation are crucial for normal embryonic development and cell maturation, and that deficiencies in these glycomodifications can lead to the impairment of embryogenesis and somatic stem cell differentiation in mammalians and other vertebrates [31, 32, 50-52]. Moreover, certain fucosyltransferases and sialyltransferases are preferentially expressed in hPSCs $[46,48]$, suggesting a role for these enzymes in maintenance of the pluripotency-associated profile. Although the mechanisms by which these glycosyltransferases may participate in the regulation of pluripotency and differentiation of hPSCs have not been well characterized, it is likely that their enzymatic activity orchestrates the functions of many pluripotency-related signaling molecules.

A recent report published by Jang et al. [53] described how $O$-linked glycosylation influences cellular pluripotency and somatic cell reprogramming by acting on core components of the mouse pluripotency signaling network. They provided definitive evidence that Pou5f1/ Oct 4 and Sox 2 are modified by $O$-linked-N-acetylglucosamine $(O$-GlcNAc) particularly in undifferentiated mouse embryonic stem cells (mESCs), and that the $O$ GlcNAc modification of $\mathrm{Thr}^{228}$ of Pou5fl enhances the transcriptional activity of Pou5f1 to induce many pluripotency-related genes, maintain self-renewal of mESCs and reprogram mouse embryonic fibroblasts (MEFs) [53]. Although a similar regulatory mechanism has not yet been examined in hPSCs, this study demonstrated a direct link between protein glycosylation and pluripotency regulation that is highly likely to exist in human cells as well. Interestingly, $O$-GlcNAc transferase (Ogt) has also been identified as a stable binding partner for 5-methylcytosine hydroxylases Tet1 and Tet2 in mESCs, indicating that the protein glycosylation activity of Ogt may participate in the regulation of $\mathrm{CpG}$ island methylation and thus gene expression [54]. These studies also suggested that it may be possible to manipulate pluripotency in mammalian cells for research or clinical applications by controlling protein glycosylation.

Many mitogens and morphogens play important roles in the establishment and maintenance of cellular pluripotency in hPSCs in vitro. Additionally, there are numerous growth factors and cytokines involved in the optimization of signaling circuits during cell lineage specification and normal embryonic development. One of the most commonly used growth factors for culturing hPSCs is fibroblast growth factor 2 (FGF2), which is a member 


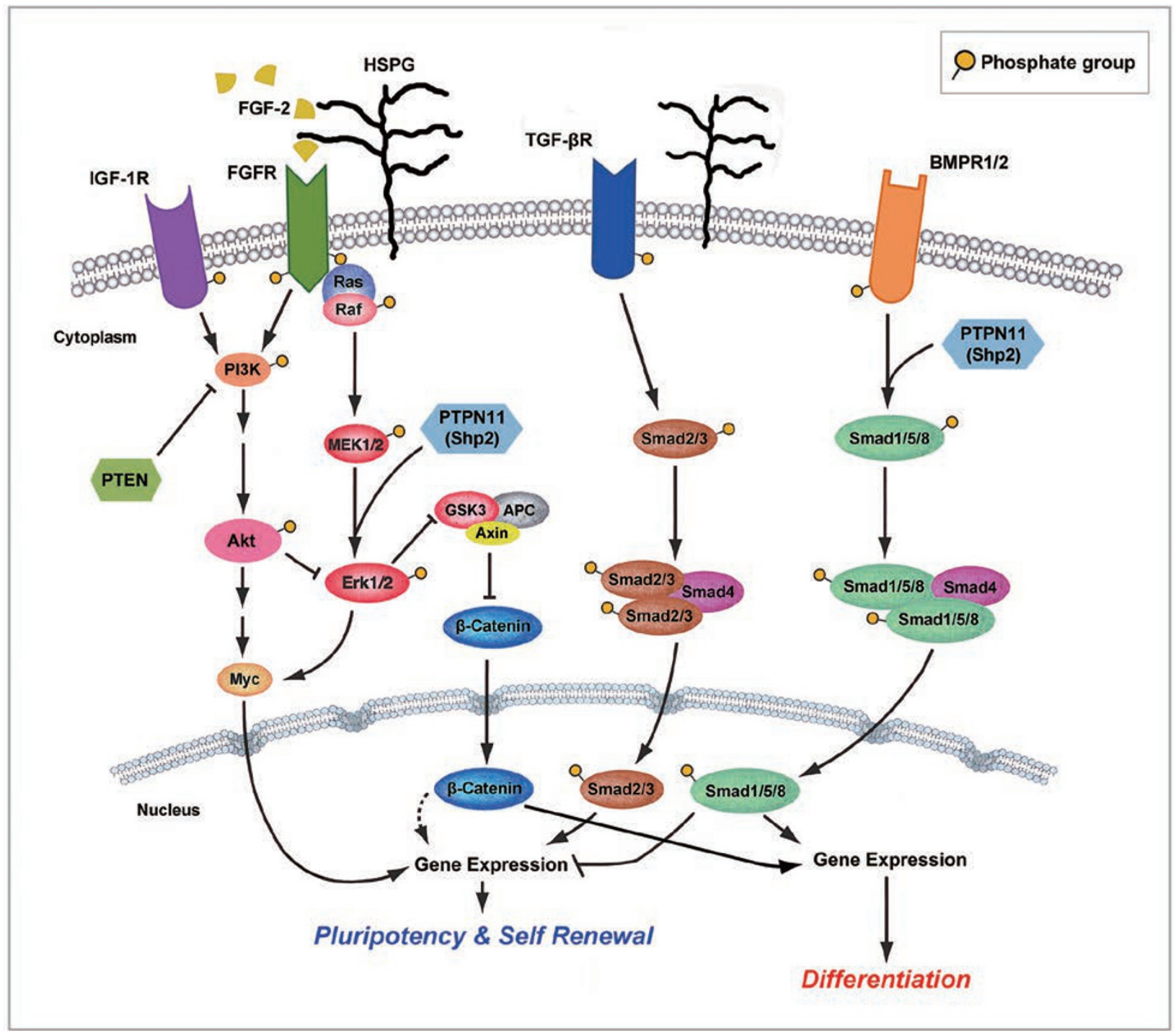

Figure 4 Cell signaling pathways governed by protein phosphorylation and critically involved in embryonic development and the regulation of pluripotent states in PSCs. Many growth factor receptors on the cell surface are receptor kinases. Upon ligand binding, these receptor kinases are fully activated and phosphorylate downstream, intracellular kinases to initiate phosphorylation signaling cascades that frequently regulate the translocation and activity of several transcription factors (e.g., Myc, $\beta$-Catenin and Smad proteins) and the expression of pluripotency- or differentiation-associated genes. These signal transduction pathways are highly interactive with each other and influenced by other proteins (e.g., HSPG) on the cell surface or in the microenvironment. Several protein phosphatases (e.g., PTEN and Shp2) that negatively control protein phosphorylation also play critical roles in the modulation of this signaling network and the differentiation potential of PSCs.

of the FGF protein family and modulates the function of multiple cell types by binding to FGF receptors (FGFRs) on the cell surface. It is known that FGF2 is a heparin sulfate-binding protein $[55,56]$, and that the magnitude of cell signaling triggered by FGF2 can be determined by the amount of heparin sulfate proteoglycans (HSPGs) on the cell surface, which facilitate the efficient binding of FGF2 to FGFRs [57]. The $N$-linked glycosylation of FGFR1 appears to interfere with the interaction between
FGFR1, FGF2 and heparin sulfate by increasing steric hindrance and reducing the binding affinity of FGFR1 to its ligands [58]. Like FGF2, other signaling factors such as Notch, Wnt proteins and epidermal growth factors (EGFs), are intimately involved in the determination of stem cell fate $[59,60]$. The activities of these key regulators of cell differentiation and their associated signaling pathways are also influenced by their own glycosylation state and extracellular HSPGs [51, 61-64]. Indeed, 
defects in protein glycosylation machinery frequently lead to the impairment of developmental signaling, the retardation of embryogenesis in animal models and the pathogenesis of human congenital disorders [31, 32, 50$52,62,65-69]$, highlighting alternative mechanisms by which protein glycosylation may regulate pluripotent and differentiated states in hPSCs.

Utility of pluripotency-associated glycosylation for regenerative medicine

Although the potential mechanisms and functional significance of protein glycosylation in the regulation of cellular pluripotency in hPSCs require further exploration, the possible utility of unique glycosylation profiles in hPSCs has been appreciated and exploited in relevant fields. To ensure the safety of cells differentiated from hPSCs for cell-based therapy, it is critical to remove residual undifferentiated hPSCs that are potentially tumorigenic. Moreover, to enhance the reproducibility and efficiency of differentiation methods, it may be desirable to select homogeneous undifferentiated hPSC populations in which all the cells have similar capacities and responses to differentiation stimuli. Differential surface glycosylation features between hPSCs and non-pluripotent cells have been used to develop methods to remove undifferentiated cells and purify differentiated cell types $[48,70]$. Also, the binding kinetics of glycan/glycoprotein-binding probes (e.g., lectins and antibodies) and the density of their ligands on the cell surface can be monitored using microfluidic devices and used to track early events during cell differentiation [71]. Protein glycosylation marks in hPSCs can thereby be considered potential targets for developing a rigorous strategy for the quality control of hPSCs and their differentiated derivatives.

\section{Protein phosphorylation in hPSCs}

\section{Protein phosphorylation and signaling cascades}

Similar to protein glycosylation, protein phosphorylation is involved in the regulation of a broad spectrum of cellular processes and states. The phosphorylation state of proteins in typical eukaryotic cells is mainly determined by the activity of protein kinases and phosphatases on their substrates. The covalent conjugation of phosphate groups to peptides frequently alters protein function by inducing conformational changes in proteins or by affecting protein-protein/enzyme-substrate interactions. Many kinases and phosphatases are also phosphorylation substrates, thereby forming mutually-dependent and hierarchically-regulated signaling loops and cascades [72]. Cell fate determination in hPSCs strongly depends on the balance between pluripotency and differentia- tion signalings. As shown in Figure 4, many signaling pathways critically involved in the embryonic development and the modulation of gene expression for cellular pluripotency and differentiation are initiated from the activation of growth factor receptors that are known receptor tyrosine kinases (RTKs; e.g., FGFR and IGF1R) or receptor serine/threonine kinases (e.g., TGF $\beta R$ and BMPR1/2). It is notable that these signaling pathways have frequent crosstalk with each other, and that the steady state of cellular pluripotency is established on top of an intricate and yet delicately-balanced molecular interaction network $[73,74]$.

\section{Regulation of pluripotency by protein phosphorylation and dephosphorylation}

In the stem cell field, many efforts are made to dissect the signaling networks regulated by protein phosphorylation in hPSCs and understand how they function as a whole to regulate cellular pluripotency and differentiation. Advances in protein mass spectrometry have enabled the global, quantitative analysis of dynamic changes in phosphorylated proteins in cells. Several recent studies used phosphoproteomic approaches to systematically investigate phosphorylated proteins in hPSCs. The study done by Swaney et al. [75] identified of more than 11 000 unique phosphopeptides that corresponded to more than 10000 non-redundant phosphorylation sites in hESCs. Five of these phosphorylation sites were localized to POU5F1 (also known as OCT4) and SOX2 [75]. Van Hoof et al. [76] discovered that the phosphorylation state of about $50 \%$ of protein phosphorylation sites that they identified was dynamically regulated and rapidly changed in hESCs, responding to the induction of differentiation. These phosphorylation sites included three consecutive serine residues that flank an upstream SUMOylation site and regulate the phosphorylationdependent SUMOylation of SOX2 [76]. Moreover, the comparison between the proteomes and phosphoproteomes of a small number of hESCs and hiPSCs revealed functionally-associated differences in protein expression and phosphorylation in these two types of hPSCs, possibly related to residual regulatory characteristics of the somatic cells used for generating the hiPSCs [10]. It is therefore plausible that the protein phosphorylation modulates pluripotency in hPSCs by acting on the key factors, which are essential for pluripotency in addition to numerous signal transduction molecules. Indeed, there have been several reports suggesting that protein phosphorylation that acts directly on POU5F1, NANOG, SOX2, KLF4 and MYC may affect the function of these transcription factors in the regulation of cellular pluripotency [77]. Variations in protein expression and the phos- 
phorylation state of different hPSC lines may affect their responses to environmental stimuli. Like glycoproteins, phosphoproteins appear to convey information regarding the pluripotent state of hPSCs. Specific types of protein phosphorylation are less likely to be identified as "pluripotency-associated" biomarkers due to the lower degree of structural complexity of protein phosphorylation compared with that of protein glycosylation. However, it is likely that the phosphoproteome or a subset of phosphoproteins could provide a sensitive and useful biomarker for monitoring pluripotency and differentiation in hPSCs.

It is clear that both kinases and phosphatases play critical roles in the proper operation of cell signaling mediated by protein phosphorylation. Unlike many kinases that have been well studied in somatic cells and hPSCs, the importance of protein phosphatases in the regulation of cellular pluripotency is less appreciated. Despite the overwhelming amount of attention that has been focused on kinases in mammalian PSCs, protein phosphatases (alkaline phosphatase in particular) remain one of the earliest-discovered and most commonly used biomarkers for cellular pluripotency $[78,79]$, indicating the potential functional significance of protein phosphatases in PSCs. Indeed, emerging data have shown that several phosphatases (e.g., PTEN and Shp2) are important for the differentiation capacity and lineage specification of human and murine PSCs. Moreover, suppression of these protein phosphatases inhibits hPSC exit from the pluripotent state during differentiation [80-82]. These studies also illustrate how phosphatases affect cellular pluripotency by altering protein phosphorylation in various signaling pathways, and establish a strong rationale for the development of a strategy to stabilize pluripotency by specific interference with the activity of certain phosphatases.

Phosphorylation signaling is potentially influenced by genetic variations and proteoglycans in hPSCs

Numerous studies have suggested that the expression and activity of many protein kinases and phosphatases can be influenced by single nucleotide polymorphisms

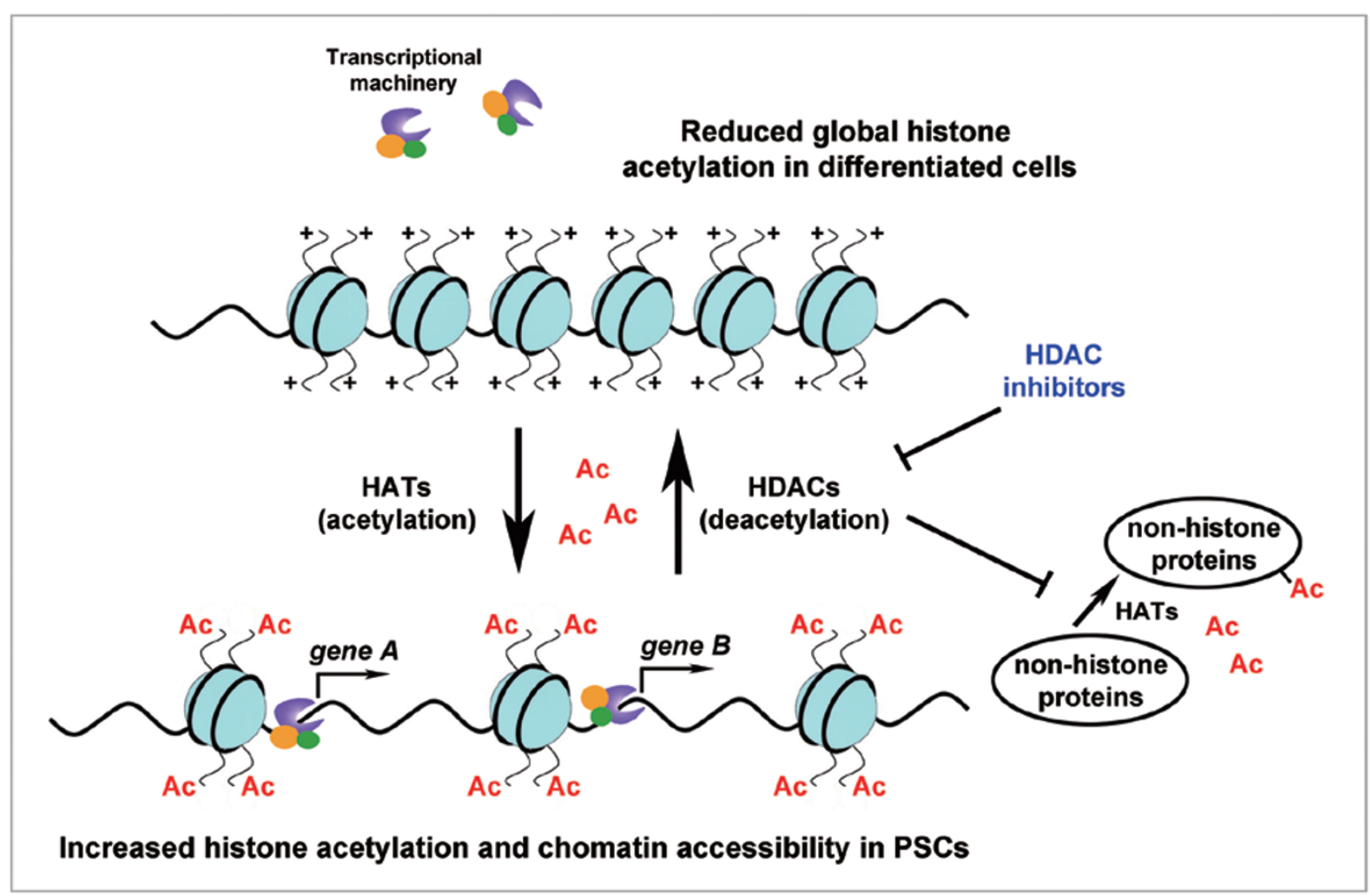

Figure 5 The antagonistic actions of HATs and HDACs are required for regulating the acetylation of histone and non-histone proteins in many types of mammalian cells, including mouse and human PSCs. HATs transfer acetyl groups onto proteins and HDACs remove the acetyl groups. The acetylation state of histones affects chromatin structure and dictates the accessibility of promoter regions to the transcriptional machinery and the activation of gene expression. In the pluripotent state, cells appear to have higher levels of global histone acetylation and chromatin accessibility for transcriptional machinery. The acetylation state and functions of many non-histone proteins are also controlled by HATs and HDACs. 
(SNPs) or rare point mutations existing in human genomes. These genetic variations are functionally associated with the differential regulation of signal transduction and the unequal susceptibility to a variety of disorders among different individuals [83-91]. A global analysis of SNP marks in hPSC genomes revealed that the duplication or deletion of several genes (e.g., NRAS, AKT3, RASA3 and DUSP 15) involved in phosphorylation signaling networks frequently occurs in hPSCs during cellular reprogramming and long-term culture [92]. Although correlations between the differentiation capacity of hPSCs and these genetic variations have not been systematically examined, it is feasible that cellular pluripotency and differentiation propensity may differ in different hPSC lines partially due to intrinsic genetic variation that alters cell signaling mediated by protein phosphorylation.

As mentioned earlier, protein glycosylation and extracellular proteoglycans are critical for modulating growth factors and plasma membrane-bound receptor kinases to which they bind (Figure 4). This suggests that protein glycosylation and phosphorylation are highly interactive in hPSCs, and that the perturbation of glycomodifications or glycoprotein expression on the cell surface may be frequently accompanied by drastic changes in phosphorylation signaling networks and the pluripotent state.

\section{Protein acetylation in hPSCs}

\section{Histone/non-histone proteins and protein acetylation}

As shown in Figure 5, two types of key regulators, histone acetyltransferases (HATs) and histone deacetylases (HDACs), dynamically control the acetylation state of histones. The antagonistic actions of these enzymes on histones serve as an important mechanism for the epigenetic regulation of gene expression [93]. In addition to histones, many non-histone proteins have been identified as the substrates of HATs and HDACs [94]. There are numerous examples showing that the acetylation state of proteins is highly relevant to their stability and activity in cells. Defects in protein acetylation frequently result in severe abnormalities of development and physiology due to the dysregulation of gene expression and protein function in animal models, and are pertinent to the pathogenesis of many human diseases [95-97]. In addition, undifferentiated mESCs appear to have a higher level of global histone acetylation with transcriptional hyperactivity as compared to their differentiated derivatives [98]. These observations not only suggest the importance of protein acetylation in controlling cellular state and differentiation capacity, but also rationalize approaches to potentially correct these abnormalities or treat diseases by targeting HATs and HDACs.
Regulation of pluripotency by protein acetylation and HDAC inhibitors

There are five families of HDACs expressed in mammalian cells, including class I (HDAC1, 2, 3, and 8), class IIa (HDAC4, 5, 7, and 9), class IIb (HDAC6 and 10), class III (SIRT1-7) and class IV (HDAC11). Efforts studying HDACs as therapeutic targets in malignant cells have led to the development of a series of smallmolecule inhibitors, particularly inhibitors of class I and II HDACs, that block their ability to catalyze protein deacetylation [95]. One of the most well-known HDAC inhibitors is suberoylanilide hydroxamic acid (SAHA, Vorinostat), currently used as an anticancer therapeutic agent to treat patients with cutaneous T-cell lymphoma.

Interestingly, many HDAC inhibitors, including SAHA, valproic acid (VPA), trichostatin A (TSA) and sodium butyrate, are known to significantly enhance the efficiency of reprogramming mouse or human somatic cells into iPSCs [99-102], suggesting that suppression of HDAC activity and regulation of protein acetylation is important for the establishment and modulation of cellular pluripotency. Among these HDAC inhibitors, VPA also enables the efficient induction of iPSCs from MEFs without the expression of exogenous Myc, as well as the successful reprogramming of human dermal fibroblasts (HDFs) to generate hiPSCs with ectopic expression of only POU5F1 and SOX2 [100]. Although sodium butyrate appeared to substitute for ectopically-expressed MYC and KLF4 and remarkably increased the yield of hiPSCs from HDFs [101], it facilitated miPSC production in a Myc-dependent fashion and adversely affected reprogramming efficiency in the absence of ectopicallyexpressed Myc in MEFs [102]. Despite these reported discrepancies between mouse and human somatic cells, it is generally agreed that treatment of somatic cells with HDAC inhibitors during reprogramming can induce changes that drive cells toward the pluripotent state due to increased histone acetylation and activation of gene expression. Two recent studies showed that the nucleosome remodeling and deacetylation (NuRD) complex containing HDAC1 and HDAC2 is functionally associated with suppression of pluripotency-associated gene expression and promotion of lineage commitment in mESCs $[103,104]$. These studies reiterate the significant role of HDACs in the regulation of cellular pluripotency and suggest that HDACs regulate pluripotency through a mechanism involving chromatin remodeling.

It has been shown that many deacetylases are localized to the cytoplasm or frequently shuttle between the cytoplasm and nucleus [105]. This cytoplasmic localization provides these enzymes with the opportunity to interact with many non-histone proteins to modulate 


\section{Arginine Methylation}
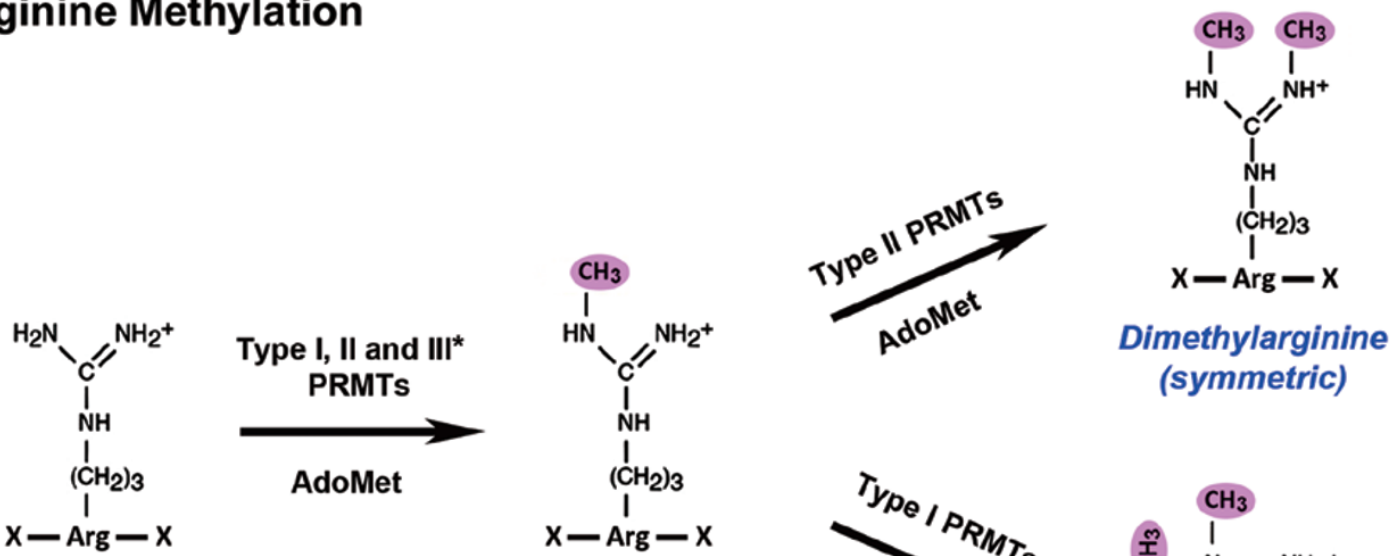

Monomethylarginine
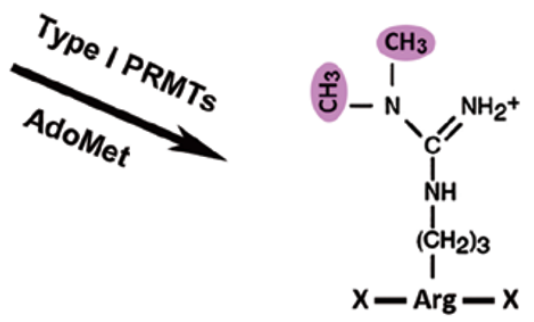

Dimethylarginine

(asymmetric)

\section{Lysine Methylation}

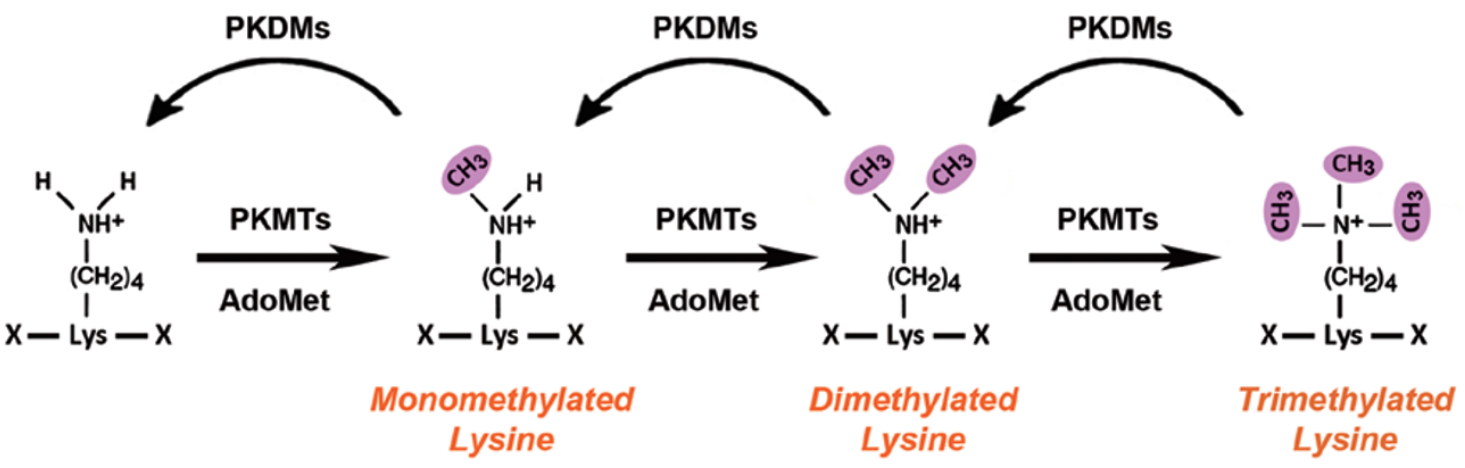

Figure 6 The biochemical reactions of arginine and lysine methylation are catalyzed by protein arginine methyltransferases (PRMTs) and protein lysine methyltransferases (PKMTs) in cells. Depending on the number of methyl groups and types of methyltransferases that are involved in methylation, the reactions can result in the production of monomethylarginine, symmetric dimethylarginine, asymmetric dimethylarginine, monomethylated, dimethylated or trimethylated lysine in peptides. The asterisk indicates the ability of human type III PRMT (PRMT7) to convert arginine residues of proteins into monomethylarginines but not any form of dimethylarginines is debatable.

their acetylation state and function. Among all the class I, class II and class IV HDACs, HDAC3, 4, 5, 6, 7, 9, 10 have well-characterized non-histone substrates. Many of these non-histone substrates (e.g., TP53, MEF2, RUNX2, STAT1, STAT3, NFKB1, CTNNB1/ $\beta$-catenin, HIF1A and tubulin) are intrinsically involved in the regulation of cellular pluripotency, proliferation and differentiation $[96,105]$. In fact, several reports have indicated the importance of HDAC-mediated deacetylation of nonhistone proteins for lineage specification and normal differentiation of particular cell types from stem cells [106108]. Jain et al. [109] recently reported that the acetylation of TP53 at Lys ${ }^{373}$ leading to the stabilization of TP53 plays an important role in the initiation of differentiation in hESCs. As HDAC inhibitors (e.g., TSA) enhance the acetylation of TP53 at $\mathrm{Lys}^{373}[110,111]$, it is possible 
that treatment with these inhibitors may influence cell fate decisions in cells that undergo reprogramming or differentiation. This may occur through modulating the post-translational regulation of TP53 and other signaling molecules that are relevant to embryogenesis or pluripotency, in addition to altering chromatin structures and gene expression.

Besides HDAC1-11, the sirtuins (SIRT1-7, class III HDACs) regulate the deacetylation of numerous proteins. Sirtuins are a unique group of $\mathrm{NAD}^{+}$-dependent protein deacetylases that are virtually unaffected by most HDAC inhibitors currently available [112]. To understand the potential roles of sirtuins in the context of pluripotency regulation, several studies have characterized SIRT1-deficient hESCs and Sirt1-knockout mESCs. SIRT1 knockdown in hESCs or knockout in mESCs appears to have negligible effects on the expression of pluripotency factors prior to the induction of differentiation $[113,114]$. However, downregulation of SIRT1 occurs in hESCs undergoing differentiation and it leads to the effective expression of developmental genes that are epigenetically repressed by the SIRT1-mediated deacetylation of histones $\mathrm{H} 3$ and $\mathrm{H} 4$ in pluripotent hESCs [113]. In addition, hESCs with SIRT1 knockdown show greater changes in the expression of pluripotency-related and differentiation-related genes in response to differentiation cues, compared to wild-type hESCs [113]. Interestingly, Sirt1 deficiency impedes the downregulation of pluripotency factors, delays the induction of differentiation factors, and compromises hematopoietic lineage capacity in mESCs undergoing differentiation [114]. Although more studies are needed to comprehensively understand how SIRT1 exerts its function on the determination of cell fate in different types of PSCs, these findings indicate that the regulation of histone acetylation by sirtuins may greatly influence differentiation programs and lineage commitment.

It has been shown that SIRT1 can suppress TP53 (p53)-mediated apoptosis by deacetylating and inhibiting TP53 $[115,116]$. SIRT2 is also implicated in regulating the activity of several transcription factors, including TP53 and FOXO1 [117-119]. Consistent with these studies, SIRT1 alleviates the Tp53-mediated suppression of Nanog expression by blocking Tp53 acetylation and nuclear translocation in mESCs [120]. In addition, the deacetylation of FOXO1 by SIRT2 leads to a reduction in mouse adipocyte differentiation $[119,121]$. A more recent study reveals that SIRT1 is elevated during cell reprogramming and facilitates the generation of miPSCs partially through the negative regulation of $\mathrm{Tp} 53$ acetylation and transcriptional activity [122], suggesting that the SIRT1-mediated protein deacetylation of non-histone substrates may play an important role in the establishment and maintenance of cellular pluripotency in hPSCs. The deacetylation and modulation of different nonhistone proteins by sirtuins during cell differentiation also provides a possible explanation for the perplexing and somewhat contradictory observations of phenotypic alterations induced by SIRT1 deficiency in hESCs and mESCs. Indeed, all the sirtuins have been shown to interact with non-histone substrates [123], which may vary in amount and composition in different cells.

Given the fact that most HDAC inhibitors can target multiple members within the HDAC family, the identification of any $\operatorname{HDAC}(\mathrm{s})$ and its substrate(s) fundamentally associated with pluripotency or differentiation remains an important and challenging task. Hopefully, the discovery of such HDACs will allow us to better understand the influence of HDAC inhibitors in hPSCs and how to select or design HDAC inhibitors for different purposes in regenerative medicine. In addition, the significance of HATs and their mechanism of action with regard to the regulation of cellular pluripotency in hPSCs could be equally interesting. Recent reports have shown that defects in HATs, including Mof (Males absent on the first, also known as Myst1 or Kat8), Trrap (Transformation/transcription domain-associated protein) and Ep300 (p300), result in phenotypical alterations in cellular pluripotency and differentiation in $\mathrm{mESCs}$ [124-126]. In addition, the conditional deletion of Trrap depletes the hematopoietic stem cell pool in mice [127]. Interestingly, the transcriptional activity of Krüppellike factor 4 (KLF4), one of the transcriptional factors used for producing hiPSCs [5], is regulated by EP300mediated acetylation in human cancer cells [128]. These findings highlight the need to examine HATs in hPSCs to understand their potential roles in the regulation of pluripotency in human cells.

Pluripotency is potentially affected by interactions between protein acetylation and phosphorylation

Like the crosstalk between glycosylation and phosphorylation of proteins, there are many identified interactions between protein acetylation and phosphorylation signaling. For example, the translocation of class IIa HDACs is under the control of $\mathrm{Ca}^{2+} /$ calmodulindependent protein kinase (CaMK), cAMP/protein kinase A (PKA) and protein kinase D (PKD)-mediated phosphorylation [129-133]. The phosphorylation of HDAC3 at $\mathrm{Ser}^{424}$ reduces its deacetylase activity and is antagonistically regulated by casein kinase II (CK2) and serine/threonine protein phosphatase 4 (PP4) [134]. The inactivation of SIRT2 through inhibitory phosphorylation at $\mathrm{Ser}^{368}$ is mediated by cyclin-dependent kinases 
(CDK), CDK1, 2 and 5 [135, 136]. HDAC1, 3 and 6 are implicated in the enhancement of AKT signaling through their specific interactions with protein phosphatase 1 (PP1) [137] and AKT [138]. Moreover, SIRT1 (SIR2 $\alpha$ ) modulates TGF $\beta$-induced apoptosis by facilitating the deacetylation and degradation of Smad7 [139]. These potential regulatory interactions not only add another layer of complexity to the molecular mechanisms underlying cellular pluripotency regulated by protein acetylation, but also remind us that the treatment with HDAC inhibitors that selectively inhibit different types of HDACs may lead to distinct consequences in cellular reprogramming or differentiation of hPSCs.

\section{Protein methylation in hPSCs}

\section{Overview of protein methylation}

The identity of the enzymes causing protein methylation remained unknown until the heterogeneous nuclear ribonucleoprotein (hnRNP) methyltransferase 1 (HMT1, also known as RMT1) was first discovered in Saccharomyces cerevisiae less than 20 years ago [140]. Since then, numerous types of protein methyltransferases and their orthologs have been identified in yeast, fruit flies and mammals [141, 142]. It is now clear that protein methylation has profound influences on many biological events and that defects in protein methyltransferases may lead to severe phenotypic abnormalities during embryogenesis $[143,144]$. Two types of protein methylation, arginine and lysine methylation (Figure 6), and their relevant methyltransferases have been frequently described. There are 10 members in the protein arginine methyltransferase (PRMT) family and more than 30 members in the protein lysine methyltransferase (PKMT) family expressed by mammalian cells $[143,144]$. Like HATs, one of the most frequently described substrates for PRMTs and PKMTs is histone. Unlike acetylated lysine residues on histones, which are generally associated with the activation of gene expression, the methylation of different lysine residues on histones may lead to either activation or suppression of gene expression.

\section{Regulation of pluripotency by protein methylation}

It has been reported that the methylation of histone $\mathrm{H} 3$ lysine 4 (H3K4), H3K36 and H3K79 is associated with active gene expression [145-147], and that the methylation of histone $\mathrm{H} 3 \mathrm{~K} 9, \mathrm{H} 3 \mathrm{~K} 27$ and H4K20 is involved in gene silencing [148-151]. Due to its functional impact on

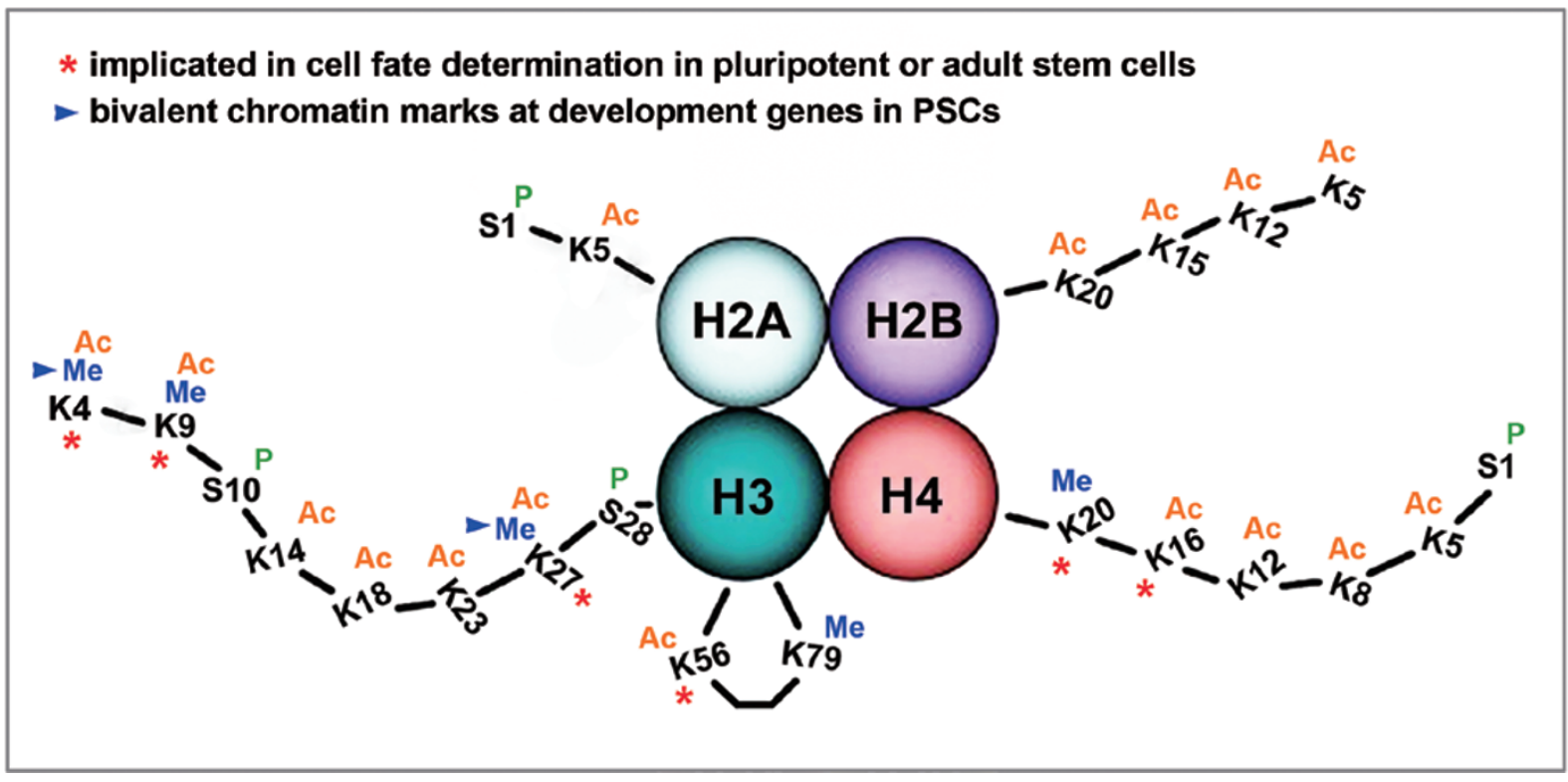

Figure 7 An illustration of amino acid residues where acetylation, methylation and phosphorylation frequently occur in core histones. Certain lysines (e.g., H3K4, H3K9 and H3K27) may be modified by either acetylation or methylation. Trimethylation of H3K4 and H3K27 gives rise to the bivalent chromatin marks found at the transcription start sites of many genes involved in lineage commitment and development in undifferentiated hPSCs. The majority of these bivalent marks resolve into one or the other at each particular gene during cell differentiation, depending on the expression state of the genes in differentiated derivatives. In general, genes induced during the differentiation of hPSCs retain the H3K4 methylation marks, and genes silenced during differentiation retain the H3K27 methylation marks. The phosphorylation of amino acid residues (e.g., H3S10 and $\mathrm{H} 3 \mathrm{~S} 28$ ) in close proximity to these lysines could influence their methylation-acetylation switch. 
transcription, it is foreseeable that histone methylation may participate in the regulation of pluripotent states by modulating the expression of pluripotency factors. In fact, several reports have described genome-wide histone methylation patterns in hESCs and the dynamic changes in bivalent chromatin marks (e.g., methylation of H3K4 and H3K27; Figure 7) that are associated with the expression levels of pluripotency and differentiation factors during cell differentiation $[152,153]$. Many recent studies further examined correlations between gene expression and the methylation states of H3K4 and H3K27 in hESCs committing to the specific cell lineages and hiPSCs reprogrammed from somatic cells [154-156]. These studies suggest that histone methylation and chromatin remodeling are critical for the cardiac and pancreatic differentiation and are highly similar between hESCs and hiPSCs. Furthermore, the data obtained from murine systems also demonstrated an essential role of Carm1 (coactivator-associated arginine methyltransferase 1)-mediated histone arginine methylation in the regulation of cellular pluripotency in mESCs $[157,158]$ and revealed the importance of histone lysine methylation for balancing quiescent and active states of hair follicle stem cells in vivo [159].

Being one of the additive PTMs, protein methylation is theoretically reversible and under the control of antagonistic reactions catalyzed by protein methyltransferases and demethylases. Unlike the intense attention paid to deacetylases in protein acetylation research, protein demethylases seem to receive much less attention than methyltransferases from researchers in relevant fields. Several studies have uncovered a requirement for H3R17/R26 methylation by methyltransferase Carm1 in the maintenance of $\mathrm{mESC}$ pluripotency $[157,158]$, the association between the aberration in mouse hair follicle stem cells and the deficiency of H3K27 methylation due to Ezh1 and Ezh2 knockouts [160], the function of Ezh1 and Ezh2 to regulate mESC pluripotency [161], and the involvement of H3K27 demethylase Kdm6a in the migration and differentiation of hematopoietic stem cells [162]. Therefore, it would be an interesting question to ask whether and how protein demethylases govern the cellular pluripotency and differentiation of mammalian PSCs. Consistent with this idea, a recent report showed that H3K36 demethylase Kdm2b substitutes for Myc and promotes miPSC production by facilitating early gene activation in reprogramming [163]. Similarly, another report showed that H3K27 demethylases KDM6A and KDM6B modulate the differentiation of definitive endoderm from hESCs by activating WNT3 and its relevant signaling pathways [164].

Similar to protein acetylation on non-histone sub- strates, it is also anticipated that non-histone proteins can be regulated by protein methylation. Indeed, the methylation of many non-histone proteins (e.g., TP53, ESR1, NFKB1, E2F1, RB and STAT3) that have critical functions in signal transduction or transcriptional regulation has been linked to the activation or suppression of their functions [165]. An important mechanism by which the methylation of non-histone proteins modulates cell signaling is through regulating protein-protein interaction between components of signaling networks. For example, the interaction of TP53 with Tip60, L3MBTL1, TP53BP1, and SIRT1 is critical for the activity of TP53 and is influenced by its methylation [166-168]. In addition, it has been shown that the Set7/9-mediated methylation of $\mathrm{Rb}$ facilitates the interaction between $\mathrm{Rb}$ and HP1, critical for Rb-dependent cell cycle arrest, transcriptional repression, and differentiation of myoblasts [169]. This suggests that protein methylation could also participate in the regulation of differentiation by affecting non-histone molecules and their associated signaling networks in hPSCs.

As shown in Figure 7, lysine residues where acetylation primarily occurs in core histone proteins are in close proximity to several serine phosphorylation sites. In addition, certain lysines may be modified by either acetylation or methylation. The competition between acetylation and methylation occurring on $\mathrm{H} 3 \mathrm{~K} 27$ acts as an antagonistic switch for the gene expression repressed by polycomb group proteins [170], while kinase signaling leading to the phosphorylation of nearby amino acid residues (e.g., $\mathrm{Ser}^{28}$ ) can also influence the methylationacetylation switch of H3K27 [171]. These findings indicate that histone acetylation and phosphorylation may profoundly affect the expression of many genes regulated by the bivalent chromatin methylation marks in hPSCs. The amino acid residues subjected to acetylation, methylation and phosphorylation in non-histone proteins are also likely to have similar interactions that directly determine protein functions. Therefore, the actual mechanisms underlying protein methylation and its phenotypic consequences in the context of cellular pluripotency and differentiation are likely far more complicated than what was originally thought.

\section{Concluding remarks and future directions}

Cellular pluripotency is a fascinating feature of hPSCs that has drawn the attention of researchers from multiple fields. As hESCs and hiPSCs continue to hold great promise for the success of regenerative medicine, it is crucial for us to dissect the molecular mechanisms underlying cellular pluripotency in human cells from 
additional perspectives, not just those involving genomics, epigenetics and transcriptomics. Emerging evidence shows that PTMs profoundly influence the regulation of cellular pluripotency through a variety of mechanisms. The complexity of PTMs provides many accessible targets and more possibilities for characterizing hPSCs and directing their differentiation. Like the requirement for protein-protein interaction between POU5F1, SOX2 and a stem cell coactivator complex for the maintenance and establishment of cellular pluripotency [172], there could be many novel and important protein functions that rely on appropriate PTMs and cannot be directly identified at the transcriptional or translational levels in stem cells. This necessitates comprehensive investigations of PTMs in hPSCs to uncover critical and yet unknown mechanisms that are responsible for tuning pluripotencyassociated signaling and cellular plasticity in hPSCs.

In this review, we have summarized many intriguing findings with regard to four major types of PTMs in the context of cellular pluripotency of hPSCs. In addition to what we have discussed here, there are other types of PTMs (e.g., ubiquitination and SUMOylation) that occur in human cells and have well-documented roles in the maintenance of normal function of various proteins and the integrity of cell signaling pathways. Their potential roles in the regulation of cellular pluripotency $[173,174]$ merit further exploration. Due to the high level of complexity associated with the distinct properties and different functionalities of different PTMs on various types of proteins, generalizing the effects of different PTMs on the regulation of cellular pluripotency may be nearly impossible. With our review, we hope to highlight this complexity and remind our audience that alterations in PTMs can greatly impact cellular pluripotency and should be considered when stem cells are subjected to manipulations for research and clinical purposes. We believe that in the near future many more important discoveries will be made by studying PTMs in human stem cells, and that the investigation of pluripotency-associated PTMs will be a valuable approach to understanding these remarkable cells.

\section{Acknowledgments}

Y-C Wang is supported by the Marie Mayer Foundation, CIRM (TR1-01250) and NIH (R33 MH087925). SEP and JFL are supported by CIRM (RT1-01108, TR1-01250, and CL1-00502), NIH (R33 MH087925) and the Esther O'Keeffe Foundation.

\section{References}

1 Hunter T. Tyrosine phosphorylation: thirty years and counting. Curr Opin Cell Biol 2009; 21:140-146.
2 Ciechanover A. Proteolysis: from the lysosome to ubiquitin and the proteasome. Nat Rev Mol Cell Biol 2005; 6:79-87.

3 Deribe YL, Pawson T, Dikic I. Post-translational modifications in signal integration. Nat Struct Mol Biol 2010; 17:666672.

4 Tachibana M, Amato P, Sparman M, et al. Human embryonic stem cells derived by somatic cell nuclear transfer. Cell 2013; 153:1228-1238.

5 Takahashi K, Tanabe K, Ohnuki M, et al. Induction of pluripotent stem cells from adult human fibroblasts by defined factors. Cell 2007; 131:861-872.

6 Chin MH, Pellegrini M, Plath K, Lowry WE. Molecular analyses of human induced pluripotent stem cells and embryonic stem cells. Cell Stem Cell 2010; 7:263-269.

7 Guenther MG, Frampton GM, Soldner F, et al. Chromatin structure and gene expression programs of human embryonic and induced pluripotent stem cells. Cell Stem Cell 2010; 7:249-257.

8 Muller FJ, Laurent LC, Kostka D, et al. Regulatory networks define phenotypic classes of human stem cell lines. Nature 2008; 455:401-405.

9 Munoz J, Low TY, Kok YJ, et al. The quantitative proteomes of human-induced pluripotent stem cells and embryonic stem cells. Mol Syst Biol 2011; 7:550.

10 Phanstiel DH, Brumbaugh J, Wenger CD, et al. Proteomic and phosphoproteomic comparison of human ES and iPS cells. Nat Methods 2011; 8:821-827.

11 Bock C, Kiskinis E, Verstappen G, et al. Reference maps of human ES and iPS cell variation enable high-throughput characterization of pluripotent cell lines. Cell 2011; 144:439-452.

12 Nazor KL, Altun G, Lynch C, et al. Recurrent variations in DNA methylation in human pluripotent stem cells and their differentiated derivatives. Cell Stem Cell 2012; 10:620-634.

13 Osafune K, Caron L, Borowiak M, et al. Marked differences in differentiation propensity among human embryonic stem cell lines. Nat Biotechnol 2008; 26:313-315.

14 Chang KH, Nelson AM, Fields PA, et al. Diverse hematopoietic potentials of five human embryonic stem cell lines. Exp Cell Res 2008; 314:2930-2940.

15 Chetty S, Pagliuca FW, Honore C, Kweudjeu A, Rezania A, Melton DA. A simple tool to improve pluripotent stem cell differentiation. Nat Methods 2013; 10:553-556.

16 Hanay MS, Kelber S, Naik AK, et al. Single-protein nanomechanical mass spectrometry in real time. Nat Nanotechnol 2012; 7:602-608.

17 Witze ES, Old WM, Resing KA, Ahn NG. Mapping protein post-translational modifications with mass spectrometry. Nat Methods 2007; 4:798-806.

$18 \mathrm{Wu}$ M, Singh AK. Single-cell protein analysis. Curr Opin Biotechnol 2012; 23:83-88.

19 Yates JR, Ruse CI, Nakorchevsky A. Proteomics by mass spectrometry: approaches, advances and applications. Annu Rev Biomed Eng 2009; 11:49-79.

20 Froehlich JW, Dodds ED, Wilhelm M, Serang O, Steen JA, Lee RS. A classifier based on accurate mass measurements to aid large-scale, unbiased glycoproteomics. Mol Cell Proteomics 2013; 12:1017-1025.

21 Serang O, Froehlich JW, Muntel J, et al. SweetSEQer: simple de novo filtering and annotation of glycoconjugate mass spec- 
tra. Mol Cell Proteomics 2013; 12:1735-1740.

22 Shental-Bechor D, Levy Y. Folding of glycoproteins: toward understanding the biophysics of the glycosylation code. Curr Opin Struct Biol 2009; 19:524-533.

23 Haltiwanger RS. Regulation of signal transduction pathways in development by glycosylation. Curr Opin Struct Biol 2002; 12:593-598.

24 Balog CI, Mayboroda OA, Wuhrer M, Hokke CH, Deelder AM, Hensbergen PJ. Mass spectrometric identification of aberrantly glycosylated human apolipoprotein C-III peptides in urine from Schistosoma mansoni-infected individuals. Mol Cell Proteomics 2010; 9:667-681.

25 Fogel AI, Li Y, Giza J, et al. $N$-glycosylation at the SynCAM (synaptic cell adhesion molecule) immunoglobulin interface modulates synaptic adhesion. J Biol Chem 2010; 285:3486434874.

26 Reid CW, Fulton KM, Twine SM. Never take candy from a stranger: the role of the bacterial glycome in host-pathogen interactions. Future Microbiol 2010; 5:267-288.

27 Rudd PM, Elliott T, Cresswell P, Wilson IA, Dwek RA. Glycosylation and the immune system. Science 2001; 291:23702376.

28 Marth JD, Grewal PK. Mammalian glycosylation in immunity. Nat Rev Immunol 2008; 8:874-887.

29 Bustamante JJ, Gonzalez L, Carroll CA, et al. O-Glycosylated $24 \mathrm{kDa}$ human growth hormone has a mucin-like biantennary disialylated tetrasaccharide attached at Thr-60. Proteomics 2009; 9:3474-3488.

30 Varki A, Kannagi R, Toole BP. Glycosylation Changes in Cancer. In: Varki A, Cummings RD, Esko JD, etc, editors. Source Essentials of Glycobiology. $2^{\text {nd }}$ edition. Cold Spring Harbor (NY): Cold Spring Harbor Laboratory Press; 2009. Chapter 44

31 Yan Q, Yao D, Wei LL, et al. O-fucose modulates notchcontrolled blood lineage commitment. Am J Pathol 2010; 176:2921-2934.

32 Seth A, Machingo QJ, Fritz A, Shur BD. Core fucosylation is required for midline patterning during zebrafish development. Dev Dyn 2010; 239:3380-3390.

33 Moremen KW, Tiemeyer M, Nairn AV. Vertebrate protein glycosylation: diversity, synthesis and function. Nat Rev Mol Cell Biol 2012; 13:448-462.

34 Mishra S, Ande SR, Salter NW. $O$-GlcNAc modification: why so intimately associated with phosphorylation? Cell Commun Signal 2011; 9:1.

35 Andrews PW, Banting G, Damjanov I, Arnaud D, Avner P. Three monoclonal antibodies defining distinct differentiation antigens associated with different high molecular weight polypeptides on the surface of human embryonal carcinoma cells. Hybridoma 1984; 3:347-361.

36 Kannagi R, Cochran NA, Ishigami F, et al. Stage-specific embryonic antigens (SSEA-3 and -4) are epitopes of a unique globo-series ganglioside isolated from human teratocarcinoma cells. EMBOJ 1983; 2:2355-2361.

37 Kannagi R, Levery SB, Ishigami F, et al. New globoseries glycosphingolipids in human teratocarcinoma reactive with the monoclonal antibody directed to a developmentally regulated antigen, stage-specific embryonic antigen 3. J Biol Chem 1983; 258:8934-8942.
38 Pera MF, Blasco-Lafita MJ, Cooper S, Mason M, Mills J, Monaghan P. Analysis of cell-differentiation lineage in human teratomas using new monoclonal antibodies to cytostructural antigens of embryonal carcinoma cells. Differentiation 1988; 39:139-149.

39 Satomaa T, Heiskanen A, Mikkola M, et al. The $N$-glycome of human embryonic stem cells. BMC Cell Biol 2009; 10:42.

40 Hasehira K, Tateno H, Onuma Y, Ito Y, Asashima M, Hirabayashi J. Structural and quantitative evidence for dynamic glycome shift on production of induced pluripotent stem cells. Mol Cell Proteomics 2012; 11:1913-1923.

41 Draber P, Stanley P. Cytotoxicity of plant lectins for mouse embryonal carcinoma cells. Somat Cell Mol Genet 1984; 10:435-443.

42 Kosmehl H, Langbein L, Katenkamp D. Lectin histochemistry of human testicular germ cell tumors. Neoplasma 1989; 36:29-39.

43 Lee MC, Talerman A, Oosterhuis JW, Damjanov I. Lectin histochemistry of classic and spermatocytic seminoma. Arch Pathol Lab Med 1985; 109:938-942.

44 Muramatsu T, Gachelin G, Damonneville M, Delarbre C, Jacob F. Cell surface carbohydrates of embryonal carcinoma cells: polysaccharidic side chains of F9 antigens and of receptors to two lectins, FBP and PNA. Cell 1979; 18:183-191.

45 Teshima S, Hirohashi S, Shimosato Y, et al. Histochemically demonstrable changes in cell surface carbohydrates of human germ cell tumors. Lab Invest 1984; 50:271-277.

46 Tateno H, Toyota M, Saito S, et al. Glycome diagnosis of human induced pluripotent stem cells using lectin microarray. $J$ Biol Chem 2011; 286:20345-20353.

47 Toyoda M, Yamazaki-Inoue M, Itakura Y, et al. Lectin microarray analysis of pluripotent and multipotent stem cells. Genes Cells 2011; 16:1-11.

48 Wang YC, Nakagawa M, Garitaonandia I, et al. Specific lectin biomarkers for isolation of human pluripotent stem cells identified through array-based glycomic analysis. Cell Res 2011; 21:1551-1563.

49 Jones JC, Sabatini K, Liao X, et al. Melanocytes derived from transgene-free human induced pluripotent stem cells. J Invest Dermatol 2013; 133:2104-2108.

50 Murrey HE, Ficarro SB, Krishnamurthy C, Domino SE, Peters EC, Hsieh-Wilson LC. Identification of the plasticity-relevant fucose-alpha(1-2)-galactose proteome from the mouse olfactory bulb. Biochemistry 2009; 48:7261-7270.

51 Shi SL, Stanley P. Protein $O$-fucosyltransferase 1 is an essential component of Notch signaling pathways. Proc Natl Acad Sci USA 2003; 100:5234-5239.

52 Xia L, McDaniel JM, Yago T, Doeden A, McEver RP. Surface fucosylation of human cord blood cells augments binding to $\mathrm{P}$-selectin and E-selectin and enhances engraftment in bone marrow. Blood 2004; 104:3091-3096.

53 Jang $\mathrm{H}$, Kim TW, Yoon $\mathrm{S}$, et al. $O$-GlcNAc regulates pluripotency and reprogramming by directly acting on core components of the pluripotency network. Cell Stem Cell 2012; 11:62-74.

54 Vella P, Scelfo A, Jammula S, et al. Tet proteins connect the $O$-linked $N$-acetylglucosamine transferase Ogt to chromatin in embryonic stem cells. Mol Cell 2013; 49:645-656.

55 Dowd CJ, Cooney CL, Nugent MA. Heparan sulfate mediates 
bFGF transport through basement membrane by diffusion with rapid reversible binding. J Biol Chem 1999; 274:52365244.

56 Faham S, Hileman RE, Fromm JR, Linhardt RJ, Rees DC. Heparin structure and interactions with basic fibroblast growth factor. Science 1996; 271:1116-1120.

57 Yayon A, Klagsbrun M, Esko JD, Leder P, Ornitz DM. Cell surface, heparin-like molecules are required for binding of basic fibroblast growth factor to its high affinity receptor. Cell 1991; 64:841-848.

58 Duchesne L, Tissot B, Rudd TR, Dell A, Fernig DG. N-glycosylation of fibroblast growth factor receptor 1 regulates ligand and heparan sulfate co-receptor binding. J Biol Chem 2006; 281:27178-27189.

59 Hayward P, Kalmar T, Arias AM. Wnt/Notch signalling and information processing during development. Development 2008; 135:411-424.

60 Tamama K, Kawasaki H, Wells A. Epidermal growth factor (EGF) treatment on multipotential stromal cells (MSCs): Possible enhancement of therapeutic potential of MSC. J Biomed Biotechnol 2010; 2010:795385.

61 Fuerer C, Habib SJ, Nusse R. A study on the interactions between heparan sulfate proteoglycans and Wnt proteins. Dev Dyn 2010; 239:184-190.

62 Kraushaar DC, Rai S, Condac E, et al. Heparan sulfate facilitates FGF and BMP signaling to drive mesoderm differentiation of mouse embryonic stem cells. J Biol Chem 2012; 287:22691-22700.

63 Komekado H, Yamamoto H, Chiba T, Kikuchi A. Glycosylation and palmitoylation of Wnt-3a are coupled to produce an active form of Wnt-3a. Genes Cells 2007; 12:521-534.

64 Kraushaar DC, Dalton S, Wang L. Heparan sulfate: a key regulator of embryonic stem cell fate. Biol Chem 2013; 394:741751.

65 Sparks SE, Krasnewich DM. Congenital disorders of glycosylation overview. In: Pagon RA, Adam MP, Bird TD, Dolan CR, Fong CT, Stephens K, editors. GeneReviews ${ }^{\text {TM }}$ [Internet]. Seattle (WA): University of Washington, Seattle; 1993-2013. 2005 Aug 15 [updated 2012 Nov 08].

66 Kraushaar DC, Yamaguchi Y, Wang L. Heparan sulfate is required for embryonic stem cells to exit from self-renewal. $J$ Biol Chem 2010; 285:5907-5916.

67 Avsar-Ban E, Ishikawa H, Manya H, et al. Protein O-mannosylation is necessary for normal embryonic development in zebrafish. Glycobiology 2010; 20:1089-1102.

68 Weinhold B, Sellmeier M, Schaper W, et al. Deficits in sialylation impair podocyte maturation. J Am Soc Nephrol 2012; 23:1319-1328.

69 Fernandez-Valdivia R, Takeuchi H, Samarghandi A, et al. Regulation of mammalian Notch signaling and embryonic development by the protein O-glucosyltransferase Rumi. Development 2011; 138:1925-1934.

70 Tang C, Lee AS, Volkmer JP, et al. An antibody against SSEA-5 glycan on human pluripotent stem cells enables removal of teratoma-forming cells. Nat Biotechnol 2011; 29:829-834.

71 Vickers DA, Kulik M, Hincapie M, Hancock WS, Dalton S, Murthy SK. Lectin-functionalized microchannels for characterizing pluripotent cells and early differentiation. Biomicro- fluidics 2012; 6:24122-2412210.

72 Bononi A, Agnoletto C, De Marchi E, et al. Protein kinases and phosphatases in the control of cell fate. Enzyme Res 2011; 2011:329098.

73 Singh AM, Reynolds D, Cliff T, et al. Signaling network crosstalk in human pluripotent cells: a Smad2/3-regulated switch that controls the balance between self-renewal and differentiation. Cell Stem Cell 2012; 10:312-326.

74 Dalton S. Signaling networks in human pluripotent stem cells. Curr Opin Cell Biol 2013; 25:241-246.

75 Swaney DL, Wenger CD, Thomson JA, Coon JJ. Human embryonic stem cell phosphoproteome revealed by electron transfer dissociation tandem mass spectrometry. Proc Natl Acad Sci USA 2009; 106:995-1000.

76 Van Hoof D, Munoz J, Braam SR, et al. Phosphorylation dynamics during early differentiation of human embryonic stem cells. Cell Stem Cell 2009; 5:214-226.

77 Cai N, Li M, Qu J, Liu GH, Izpisua Belmonte JC. Post-translational modulation of pluripotency. J Mol Cell Biol 2012; 4:262-265.

78 Pera MF, Reubinoff B, Trounson A. Human embryonic stem cells. J Cell Sci 2000; 113(Pt 1):5-10.

79 O'Connor MD, Kardel MD, Iosfina I, et al. Alkaline phosphatase-positive colony formation is a sensitive, specific, and quantitative indicator of undifferentiated human embryonic stem cells. Stem Cells 2008; 26:1109-1116.

80 Chan RJ, Johnson SA, Li Y, Yoder MC, Feng GS. A definitive role of Shp-2 tyrosine phosphatase in mediating embryonic stem cell differentiation and hematopoiesis. Blood 2003; 102:2074-2080.

81 Wu D, Pang Y, Ke Y, et al. A conserved mechanism for control of human and mouse embryonic stem cell pluripotency and differentiation by shp2 tyrosine phosphatase. PLoS One 2009; 4:e4914.

82 Alva JA, Lee GE, Escobar EE, Pyle AD. Phosphatase and tensin homolog regulates the pluripotent state and lineage fate choice in human embryonic stem cells. Stem Cells 2011; 29:1952-1962.

83 Baral A, Kumar P, Halder R, et al. Quadruplex-single nucleotide polymorphisms (Quad-SNP) influence gene expression difference among individuals. Nucleic Acids Res 2012; 40:3800-3811.

84 Cao Q, Ju X, Li P, et al. A functional variant in the MTOR promoter modulates its expression and is associated with renal cell cancer risk. PLoS One 2012; 7:e50302.

85 Chen M, Cassidy A, Gu J, et al. Genetic variations in PI3KAKT-mTOR pathway and bladder cancer risk. Carcinogenesis 2009; 30:2047-2052.

86 Choura M, Rebai A. Applications of computational tools to predict functional SNPs effects in human $E r b B$ genes. $J$ Recept Signal Transduct Res 2009; 29:286-291.

87 Hildebrandt MA, Yang H, Hung MC, et al. Genetic variations in the PI3K/PTEN/AKT/mTOR pathway are associated with clinical outcomes in esophageal cancer patients treated with chemoradiotherapy. J Clin Oncol 2009; 27:857-871.

88 Li N, Nakamura K, Jiang Y, et al. Gain-of-function polymorphism in mouse and human Ltk: implications for the pathogenesis of systemic lupus erythematosus. Hum Mol Genet 2004; 13:171-179. 
89 Zhou XP, Marsh DJ, Morrison CD, et al. Germline inactivation of PTEN and dysregulation of the phosphoinositol3-kinase/Akt pathway cause human Lhermitte-Duclos disease in adults. Am J Hum Genet 2003; 73:1191-1198.

90 Spencer-Jones NJ, Wang X, Snieder H, Spector TD, Carter ND, O'Dell SD. Protein tyrosine phosphatase-1B gene PTPN1: selection of tagging single nucleotide polymorphisms and association with body fat, insulin sensitivity and the metabolic syndrome in a normal female population. Diabetes 2005; 54:3296-3304.

91 Fernando H, Reszka AP, Huppert J, et al. A conserved quadruplex motif located in a transcription activation site of the human c-kit oncogene. Biochemistry 2006; 45:7854-7860.

92 Laurent LC, Ulitsky I, Slavin I, et al. Dynamic changes in the copy number of pluripotency and cell proliferation genes in human ESCs and iPSCs during reprogramming and time in culture. Cell Stem Cell 2011; 8:106-118.

93 Wang Z, Zang C, Cui K, et al. Genome-wide mapping of HATs and HDACs reveals distinct functions in active and inactive genes. Cell 2009; 138:1019-1031.

94 Glozak MA, Sengupta N, Zhang X, Seto E. Acetylation and deacetylation of non-histone proteins. Gene 2005; 363:15-23.

95 Johnstone RW. Histone-deacetylase inhibitors: novel drugs for the treatment of cancer. Nat Rev Drug Discov 2002; 1:287-299.

96 Haberland M, Montgomery RL, Olson EN. The many roles of histone deacetylases in development and physiology: implications for disease and therapy. Nat Rev Genet 2009; 10:32-42.

97 Zhou B, Margariti A, Zeng L, Xu Q. Role of histone deacetylases in vascular cell homeostasis and arteriosclerosis. Cardiovasc Res 2011; 90:413-420.

98 Efroni S, Duttagupta R, Cheng J, et al. Global transcription in pluripotent embryonic stem cells. Cell Stem Cell 2008; 2:437447.

99 Huangfu D, Maehr R, Guo W, et al. Induction of pluripotent stem cells by defined factors is greatly improved by smallmolecule compounds. Nat Biotechnol 2008; 26:795-797.

100 Huangfu D, Osafune K, Maehr R, et al. Induction of pluripotent stem cells from primary human fibroblasts with only Oct4 and Sox2. Nat Biotechnol 2008; 26:1269-1275.

101 Mali P, Chou BK, Yen J, et al. Butyrate greatly enhances derivation of human induced pluripotent stem cells by promoting epigenetic remodeling and the expression of pluripotencyassociated genes. Stem Cells 2010; 28:713-720.

102 Liang G, Taranova O, Xia K, Zhang Y. Butyrate promotes induced pluripotent stem cell generation. J Biol Chem 2010; 285:25516-25521.

103 Kim JJ, Khalid O, Vo S, Sun HH, Wong DT, Kim Y. A novel regulatory factor recruits the nucleosome remodeling complex to wingless integrated (Wnt) signaling gene promoters in mouse embryonic stem cells. J Biol Chem 2012; 287:4110341117.

104 Reynolds N, Latos P, Hynes-Allen A, et al. NuRD suppresses pluripotency gene expression to promote transcriptional heterogeneity and lineage commitment. Cell Stem Cell 2012; 10:583-594.

105 Yao YL, Yang WM. Beyond histone and deacetylase: an overview of cytoplasmic histone deacetylases and their nonhistone substrates. J Biomed Biotechnol 2011; 2011:146493.

106 Gregoire S, Xiao L, Nie J, et al. Histone deacetylase 3 inter- acts with and deacetylates myocyte enhancer factor 2. Mol Cell Biol 2007; 27:1280-1295.

107 Vega RB, Matsuda K, Oh J, et al. Histone deacetylase 4 controls chondrocyte hypertrophy during skeletogenesis. Cell 2004; 119:555-566.

108 Zeng L, Xiao Q, Margariti A, et al. HDAC3 is crucial in shear- and VEGF-induced stem cell differentiation toward endothelial cells. J Cell Biol 2006; 174:1059-1069.

109 Jain AK, Allton K, Iacovino M, et al. p53 regulates cell cycle and microRNAs to promote differentiation of human embryonic stem cells. PLoS Biol 2012; 10:e1001268.

110 Luo J, Li M, Tang Y, Laszkowska M, Roeder RG, Gu W. Acetylation of p53 augments its site-specific DNA binding both in vitro and in vivo. Proc Natl Acad Sci USA 2004; 101:2259-2264.

111 Roy S, Tenniswood M. Site-specific acetylation of p53 directs selective transcription complex assembly. J Biol Chem 2007; 282:4765-4771.

112 Liu T, Liu PY, Marshall GM. The critical role of the class III histone deacetylase SIRT1 in cancer. Cancer Res 2009; 69:1702-1705.

113 Calvanese V, Lara E, Suarez-Alvarez B, et al. Sirtuin 1 regulation of developmental genes during differentiation of stem cells. Proc Natl Acad Sci USA 2010; 107:13736-13741.

$114 \mathrm{Ou}$ X, Chae HD, Wang RH, et al. SIRT1 deficiency compromises mouse embryonic stem cell hematopoietic differentiation, and embryonic and adult hematopoiesis in the mouse. Blood 2011; 117:440-450.

115 Vaziri H, Dessain SK, Ng Eaton E, et al. hSIR2(SIRT1) functions as an NAD-dependent p53 deacetylase. Cell 2001; 107:149-159.

116 Li L, Wang L, Wang Z, et al. Activation of p53 by SIRT1 inhibition enhances elimination of CML leukemia stem cells in combination with imatinib. Cancer Cell 2012; 21:266-281.

117 Peck B, Chen CY, Ho KK, et al. SIRT inhibitors induce cell death and p53 acetylation through targeting both SIRT1 and SIRT2. Mol Cancer Ther 2010; 9:844-855.

118 Langley E, Pearson M, Faretta M, et al. Human SIR2 deacetylates p53 and antagonizes PML/p53-induced cellular senescence. EMBO J 2002; 21:2383-2396.

119 Jing E, Gesta S, Kahn CR. SIRT2 regulates adipocyte differentiation through FoxO1 acetylation/deacetylation. Cell Metab 2007; 6:105-114.

120 Han MK, Song EK, Guo Y, Ou X, Mantel C, Broxmeyer HE. SIRT1 regulates apoptosis and Nanog expression in mouse embryonic stem cells by controlling p53 subcellular localization. Cell Stem Cell 2008; 2:241-251.

121 Wang F, Tong Q. SIRT2 suppresses adipocyte differentiation by deacetylating FOXO1 and enhancing FOXO1's repressive interaction with PPARgamma. Mol Biol Cell 2009; 20:801808.

122 Lee YL, Peng Q, Fong SW, et al. Sirtuin 1 facilitates generation of induced pluripotent stem cells from mouse embryonic fibroblasts through the miR-34a and p53 pathways. PLoS One 2012; 7:e45633.

123 Nakagawa T, Guarente L. Sirtuins at a glance. J Cell Sci $2011 ; \mathbf{1 2 4}: 833-838$.

124 Li X, Li L, Pandey R, et al. The histone acetyltransferase MOF is a key regulator of the embryonic stem cell core tran- 
scriptional network. Cell Stem Cell 2012; 11:163-178.

125 Zhong X, Jin Y. Critical roles of coactivator p300 in mouse embryonic stem cell differentiation and Nanog expression. $J$ Biol Chem 2009; 284:9168-9175.

126 Sawan C, Hernandez-Vargas H, Murr R, et al. HAT cofactor trrap maintains self-renewal and restricts differentiation of embryonic stem cells. Stem Cells 2013; 31:979-991.

127 Loizou JI, Oser G, Shukla V, et al. Histone acetyltransferase cofactor trrap is essential for maintaining the hematopoietic stem/progenitor cell pool. J Immunol 2009; 183:6422-6431.

128 Evans PM, Zhang W, Chen X, Yang J, Bhakat KK, Liu C. Kruppel-like factor 4 is acetylated by $\mathrm{p} 300$ and regulates gene transcription via modulation of histone acetylation. $J$ Biol Chem 2007; 282:33994-34002.

129 Backs J, Song K, Bezprozvannaya S, Chang S, Olson EN. CaM kinase II selectively signals to histone deacetylase 4 during cardiomyocyte hypertrophy. J Clin Invest 2006; 116:18531864.

130 Backs J, Backs T, Bezprozvannaya S, McKinsey TA, Olson EN. Histone deacetylase 5 acquires calcium/calmodulindependent kinase II responsiveness by oligomerization with histone deacetylase 4. Mol Cell Biol 2008; 28:3437-3445.

$131 \mathrm{Ha}$ CH, Kim JY, Zhao J, et al. PKA phosphorylates histone deacetylase 5 and prevents its nuclear export, leading to the inhibition of gene transcription and cardiomyocyte hypertrophy. Proc Natl Acad Sci USA 2010; 107:15467-15472.

$132 \mathrm{Ha} \mathrm{CH}$, Wang W, Jhun BS, et al. Protein kinase D-dependent phosphorylation and nuclear export of histone deacetylase 5 mediates vascular endothelial growth factor-induced gene expression and angiogenesis. J Biol Chem 2008; 283:1459014599.

133 Parra M, Kasler H, McKinsey TA, Olson EN, Verdin E. Protein kinase D1 phosphorylates HDAC7 and induces its nuclear export after T-cell receptor activation. J Biol Chem 2005; 280:13762-13770.

134 Zhang X, Ozawa Y, Lee H, et al. Histone deacetylase 3 (HDAC3) activity is regulated by interaction with protein serine/threonine phosphatase 4. Genes Dev 2005; 19:827-839.

135 North BJ, Verdin E. Mitotic regulation of SIRT2 by cyclindependent kinase 1-dependent phosphorylation. J Biol Chem 2007; 282:19546-19555.

136 Pandithage R, Lilischkis R, Harting K, et al. The regulation of SIRT2 function by cyclin-dependent kinases affects cell motility. J Cell Biol 2008; 180:915-929.

137 Chen CS, Weng SC, Tseng PH, Lin HP. Histone acetylationindependent effect of histone deacetylase inhibitors on Akt through the reshuffling of protein phosphatase 1 complexes. $J$ Biol Chem 2005; 280:38879-38887.

138 Zampetaki A, Zeng L, Margariti A, et al. Histone deacetylase 3 is critical in endothelial survival and atherosclerosis development in response to disturbed flow. Circulation 2010; 121:132-142.

139 Kume S, Haneda M, Kanasaki K, et al. SIRT1 inhibits transforming growth factor beta-induced apoptosis in glomerular mesangial cells via Smad7 deacetylation. J Biol Chem 2007; 282:151-158.

140 Gary JD, Lin WJ, Yang MC, Herschman HR, Clarke S. The predominant protein-arginine methyltransferase from Saccharomyces cerevisiae. J Biol Chem 1996; 271:12585-12594.
141 Boros IM. Histone modification in Drosophila. Brief Funct Genomics 2012; 11:319-331.

142 Stallcup MR. Role of protein methylation in chromatin remodeling and transcriptional regulation. Oncogene 2001; 20:3014-3020.

143 Black JC, Van Rechem C, Whetstine JR. Histone lysine methylation dynamics: establishment, regulation and biological impact. Mol Cell 2012; 48:491-507.

144 Bedford MT, Clarke SG. Protein arginine methylation in mammals: who, what and why. Mol Cell 2009; 33:1-13.

145 Bannister AJ, Schneider R, Myers FA, Thorne AW, CraneRobinson C, Kouzarides T. Spatial distribution of di- and trimethyl lysine 36 of histone $\mathrm{H} 3$ at active genes. $J$ Biol Chem 2005; 280:17732-17736.

146 Bernstein BE, Kamal M, Lindblad-Toh K, et al. Genomic maps and comparative analysis of histone modifications in human and mouse. Cell 2005; 120:169-181.

147 Pokholok DK, Harbison CT, Levine S, et al. Genome-wide map of nucleosome acetylation and methylation in yeast. Cell 2005; 122:517-527.

148 Cao R, Wang L, Wang H, et al. Role of histone H3 lysine 27 methylation in Polycomb-group silencing. Science 2002; 298:1039-1043.

149 Peters AH, O'Carroll D, Scherthan H, et al. Loss of the Suv39h histone methyltransferases impairs mammalian heterochromatin and genome stability. Cell 2001; 107:323-337.

150 Rice JC, Briggs SD, Ueberheide B, et al. Histone methyltransferases direct different degrees of methylation to define distinct chromatin domains. Mol Cell 2003; 12:1591-1598.

151 Schotta G, Lachner M, Sarma K, et al. A silencing pathway to induce H3-K9 and H4-K20 trimethylation at constitutive heterochromatin. Genes Dev 2004; 18:1251-1262.

152 Pan G, Tian S, Nie J, et al. Whole-genome analysis of histone H3 lysine 4 and lysine 27 methylation in human embryonic stem cells. Cell Stem Cell 2007; 1:299-312.

153 Zhao XD, Han X, Chew JL, et al. Whole-genome mapping of histone H3 Lys4 and 27 trimethylations reveals distinct genomic compartments in human embryonic stem cells. Cell Stem Cell 2007; 1:286-298.

154 Hong SH, Rampalli S, Lee JB, et al. Cell fate potential of human pluripotent stem cells is encoded by histone modifications. Cell Stem Cell 2011; 9:24-36.

155 Xie R, Everett LJ, Lim HW, et al. Dynamic chromatin remodeling mediated by polycomb proteins orchestrates pancreatic differentiation of human embryonic stem cells. Cell Stem Cell 2013; 12:224-237.

156 Paige SL, Thomas S, Stoick-Cooper CL, et al. A temporal chromatin signature in human embryonic stem cells identifies regulators of cardiac development. Cell 2012; 151:221-232.

$157 \mathrm{Wu} \mathrm{Q}$, Bruce AW, Jedrusik A, et al. CARM1 is required in embryonic stem cells to maintain pluripotency and resist differentiation. Stem Cells 2009; 27:2637-2645.

158 Torres-Padilla ME, Parfitt DE, Kouzarides T, Zernicka-Goetz M. Histone arginine methylation regulates pluripotency in the early mouse embryo. Nature 2007; 445:214-218.

159 Lien WH, Guo X, Polak L, et al. Genome-wide maps of histone modifications unwind in vivo chromatin states of the hair follicle lineage. Cell Stem Cell 2011; 9:219-232.

160 Ezhkova E, Lien WH, Stokes N, Pasolli HA, Silva JM, Fuchs 
E. EZH1 and EZH2 cogovern histone H3K27 trimethylation and are essential for hair follicle homeostasis and wound repair. Genes Dev 2011; 25:485-498.

161 Shen X, Liu Y, Hsu YJ, et al. EZH1 mediates methylation on histone H3 lysine 27 and complements EZH2 in maintaining stem cell identity and executing pluripotency. Mol Cell 2008; 32:491-502.

162 Thieme S, Gyarfas T, Richter C, et al. The histone demethylase UTX regulates stem cell migration and hematopoiesis. Blood 2013; 121:2462-2473.

163 Liang G, He J, Zhang Y. Kdm2b promotes induced pluripotent stem cell generation by facilitating gene activation early in reprogramming. Nat Cell Biol 2012; 14:457-466.

164 Jiang W, Wang J, Zhang Y. Histone H3K27me3 demethylases KDM6A and KDM6B modulate definitive endoderm differentiation from human ESCs by regulating WNT signaling pathway. Cell Res 2013; 23:122-130.

165 Zhang X, Wen H, Shi X. Lysine methylation: beyond histones. Acta Biochim Biophys Sin 2012; 44:14-27.

166 Kurash JK, Lei H, Shen Q, et al. Methylation of p53 by Set7/9 mediates p53 acetylation and activity in vivo. Mol Cell 2008; 29:392-400.

167 West LE, Roy S, Lachmi-Weiner K, et al. The MBT repeats of L3MBTL1 link SET8-mediated p53 methylation at lysine 382 to target gene repression. J Biol Chem 2010; 285:3772537732.

168 Huang J, Sengupta R, Espejo AB, et al. p53 is regulated by the lysine demethylase LSD1. Nature 2007; 449:105-108.
169 Munro S, Khaire N, Inche A, Carr S, La Thangue NB. Lysine methylation regulates the $\mathrm{pRb}$ tumour suppressor protein. Oncogene 2010; 29:2357-2367.

170 Pasini D, Malatesta M, Jung HR, et al. Characterization of an antagonistic switch between histone H3 lysine 27 methylation and acetylation in the transcriptional regulation of Polycomb group target genes. Nucleic Acids Res 2010; 38:4958-4969.

171 Lau PN, Cheung P. Histone code pathway involving H3 S28 phosphorylation and K27 acetylation activates transcription and antagonizes polycomb silencing. Proc Natl Acad Sci USA 2011; 108:2801-2806.

172 Fong YW, Inouye C, Yamaguchi T, Cattoglio C, Grubisic I, Tjian R. A DNA repair complex functions as an Oct4/Sox2 coactivator in embryonic stem cells. Cell 2011; 147:120-131.

173 Buckley SM, Aranda-Orgilles B, Strikoudis A, et al. Regulation of pluripotency and cellular reprogramming by the ubiquitin-proteasome system. Cell Stem Cell 2012; 11:783-798.

174 Tahmasebi S, Ghorbani M, Savage P, et al. Sumoylation of Krüppel-like factor 4 inhibits pluripotency induction but promotes adipocyte differentiation. J Biol Chem 2013; 288:12791-12804.

(a) (2) (2) This work is licensed under the Creative Commons Attribution-NonCommercial-ShareAlike 3.0 Unported License. To view a copy of this license, visit http://creativecommons.org/licenses/by-nc-sa/3.0 